\title{
Geração e juventude na era digital
}

Frank Marcon ${ }^{1}$

\section{FEIXA, Carles. De la generación @ a la \# generación: la juventud en} la era digital. Barcelona, NED, 2014. 349p.

Nos últimos anos o tema das juventudes movimentou uma série de análises nas Ciências Sociais envolvendo discussões sobre protesto, violência e era digital. Do ponto de vista conceitual, retoma-se o debate sobre a eficácia analítica desta categoria, bem como se buscam outras possibilidades de pensar o modo pelo qual se pode falar num grupo social ou fenômeno que são marcados pela transitoriedade, ao mesmo tempo em que o termo é ora inflado e ora esvaziado de significados por sua utilização em contextos muito diversos. A juventude como etapa da vida, compartilhada por uma variedade incomensurável de modos de ser jovem na contemporaneidade, é enquadrada por balizas de contextos particulares que também globalizaram tal experiência nas últimas duas décadas. Se por um lado tais experiências são complexamente distintas, por outro se tornam referencias de uma temporalidade compartilhada globalmente. Captar estas contradições e paradoxos é parte dos desafios que abrem a possibilidade de pensarmos sobre a "invenção da juventude" ao mesmo tempo em que buscamos compreender os fenômenos sociais em que os jovens estão envolvidos no presente.

Para Carles Feixa, da Universidade de Lleida, na Espanha, que se dedica ao estudo sobre jovens há mais de duas décadas, a noção de geração está na interconexão das possibilidades de aprofundarmos nossas aproximações analíticas sobre tais fenômenos. O livro De La generación @ a la \# generación: la juventude en la era digital é sua contribuição mais recente ao debate, na tentativa de analisar e compreender os significados de ser jovem no presente e os dilemas e problemas que são experimentados por aqueles que se veem inscritos nesta categorização. A temporalidade e a transitoriedade das experiências são duas características do fenômeno que indicam que esta é uma construção social de um determinado momento e de uma determinada condição de vida. É partindo de tais premissas que o autor

1 Doutor em Antropologia. Professor do Departamento de Ciências Sociais na Universidade Federal de Sergipe e coordenador do Grupo de Estudos Culturais, Identidades e Relações Interétnicas, em grupos de pesquisa do CNPq. E-mail: marconfrank@hotmail.com. 
do livro retoma o clássico conceito de "geração" como possibilidade analítica para compreender os fenômenos destas experiências e suas condicionantes.

Seu livro traz uma divisão interessante e pouco convencional, sendo composto por partes que reúnem textos produzidos em diferentes ocasiões e que retomam constantemente, e a partir de distintos formatos narrativos, o debate sobre geração e juventude, trazendo como eixo o enfoque sobre o que ele denominada como "juventude na era digital". Assim, Prólogo; Discursos; Cenas; Relatos e Epílogo compõe um livro que pode ser lido também em suas partes autônomas. Alguns dos capítulos foram publicados em outras versões e formatosno curso da última década, com importantes colaboradores dos estudos sobre juventudes, como: Ariadna Fernandez-Planells, Carmen Leccardi, Monica Figueras, Oriol Ramaní, Pam Nilan e Yanko González. 0 autor considera que este livro é uma espécie de atualização e continuação das suas discussões realizadas anteriormente, como em De Jóvenes, Bandas y Tribos, de 1998. A particularidade deste livro é o modo como o autor avança com a ideia de geração neste contexto de era digital, tomando-a como possibilidade analítica para conceituar um modo de vida compartilhado e representado em um dado momento pelo símbolo @ (arroba) e num outro pelo símbolo \# (hashtag). Para Feixa, ambos se tornaram signos geracionais surgidos a partir do advento dos microcomputadores pessoais e da internet. Feixa discorre sobre como tais signos aparecem nos teclados de digitação e como chegam aos computadores, passandoa ser utilizadosde modo icônico na web. A partir de meados dos anos noventa, o indexador @, dos endereços eletrônicos de email, se tornou símbolo da internet e uma marca de seus usuários. Em fins da primeira década do século XXI, o símbolo \# se tornou símbolo da comunicação social em rede e indexador de interesses comuns agregados à rede mundial de computadores. Para o autor, sua concepção de "geração @” é uma referência" aos jovens que tem nascido e crescido na era digital, ou seja, à geração da rede" (p. 15) e o uso da noção "geração \#" se aplica aos jovens que vivenciam a generalização da web social, ou seja, da informação e da comunicação em rede, da hiperdigitalizaçãoe das redes sociais na internet. Se o @ simboliza a emergência de uma referência de comportamento cibercultural, que a partir de meados dos anos noventa passa a fazer parte da vida dos jovens em suas atividades de estudo, de trabalho e de lazer através dos conteúdos de produção digital, lógicas de produção e consumo desmaterializadas, como uso de microcomputadores; o \# significa a expansão para o uso social das conexões em rede, o uso da internet em dispositivos móveis, a intensidade dos fluxos e a lógica da instantaneidade do 
compartilhamento social e das referências temáticas dispersas numa web global. Os dois símbolos são entendidos como signos geracionais por Feixa, como referências distintas de modos de atuar e representar o mundo na era digital por parte dos jovens. 0 que não significa que tais gerações não estejam marcadas por continuidades e complementaridades alargadas entre elas, quando podem também ser qualificadas pela noção de "geração digital". Porém, Feixa destaca certas diferenças nos modos de entender o mundo e de atuar nele, entre aqueles que nasceram nos anos setenta e oitenta e foram socializados ao tempo do advento da internet e aqueles que nasceram nos noventa em diante, após a intensificação da internet e da digitalização, experimentando novas formas de socialização, de diversão, de estudo, de trabalho e de fazer política associado ao uso cotidiano das redes sociais, como: facebook, twiter e whatsapp.

Concentrando-se em outros exercícios analíticos sobre geração, o autor consideraque a categoria juventude abrange pessoas em franjas de idade, que em diferentes culturas pode se dilatar mais para um lado ou para outro a depender de quando se considera o período da infância e da vida adulta, ou seja, que a franja pode ser uma baliza, que se percepciona numa tendência global hegemônica e oficial de delimitação, mas não abarca as singularidades e a pluralidade do que pode se querer dizer sobre elas. Por isso, "nosso interesse centra na construção social da identidade, nos jovens como atores sociais criativos, no consumo cultural e nos movimentos sociais, em definitiva, no caráter distintivo das culturas juvenis locais em um mundo globalizado" (p. 33). Eu diria que mesmo quando algumas hegemonias conceituais se tornam referencias mundiais, como as noções sobre adolescência e a faixa etária que define quem é criança, jovem ou adulto, nós precisamos interessar-nos também pelas percepções plurais de como elas são acionadas e entendidas. O interessante é entender como estes processos sociais de significação se constituem, são manifestos, são praticados e como o fenômeno é ao mesmo tempo globalizado e localizado, homogêneo e plural. 0 conceito de juventude se globalizou e se alargou nas últimas décadas, ultrapassando a experiência dos próprios jovens e, por mais que as suas práticas não sejam globais, alguns sentidos destas práticas se universalizaram como juvenis, extrapolando as experiências daqueles jovens de carne e osso (DEBERT, 2010). Feixa critica a ideia de que possamos falar em uma juventude global numa cultura global ou a ideia de que a juventude se globalizou, afirmando que "as culturas juvenis são sempre e enfaticamente locais, pese que seus artefatos tenham origem global" ( $p$. 41). Ou seja, aideia é que "a juventude global, deve ser entendida como um coletivo híbrido - tanto a nível local, quanto a nível global - que 
constitui sua subjetividade a partir dos materiais providos por suas culturas, consumos, resistências, transnacionalismos e digitalismos globais ou globalizados". (FEIXA, p. 46).

Investindo na análise sobre "o conceito de geração nas teorias da juventude", Feixa analisa os debates clássicos sobre o conceito, destacando a ideia de que "Mannheim considerava às gerações como dimensões analíticas úteis para o estudo tanto das dinâmicas da mudança social", quanto uma "colisão entre o tempo biográfico e o tempo histórico" (p. 51). De outro modo, também traz o argumento de como os jovens de idade e classes sociais aproximadas pensam a si mesmos como geração particular. Feixa recorre à Gramsci para falar em "consciência geracional" (p. 53), reforçando a ideia de um senso coletivo sobre o modo de vivenciar o mundo em um determinado momento e condição, que pode ou não estar presente em um dado contexto. De Ortega y Gasset, destaca o argumento de que as pessoas nascidas em uma mesma época compartilham "uma 'mesma sensibilidade vital', oposta à geração prévia e a posterior, sensibilidade que define sua 'missão histórica'” (p. 59). Neste sentido, Feixa avança numa perspectiva revisionista e reflexiva sobre a operacionalidade do conceito de geração, fazendo um exercício de análise sobre os processos geracionais, descrevendo como diferentes gerações se representaram, foram representadas e se sobrepuseram ou inauguraram suas próprias consciências de juventude, embora alerte que "as gerações não são estruturas compactas, senão apenas referentes simbólicos que identificam vagamente aos agentes socializados nas mesmas coordenadas temporais" (p. 122). Nas suas reflexões, no capítulo "Geração @: a juventude na era digital", Feixa diz que a sensação é a de que vivemos a era digital todos ao mesmo tempo e de que tudo se sucede em tempo real, embora possamos falar em diferentes identidades de estilo versus diferentes sensibilidades geracionais, sabendo que as escalas não são de abrangência universalizada. Vivemos tempos paradoxais, pois de um lado assedemos ao hipertexto, as tecnologias e a intensa produção simbólica, e de outro lado vivemos as agruras da precarização do emprego e suas consequências econômicas, sociais, culturais e políticas. Entre os jovens o empoderamento é cada vez mais simbólico, ao mesmo tempo em que háuma maior perda de empoderamento material, como diria Martin-Barbero (2008).

Na segunda parte do livro, denominada "Cenas", Feixa discorre sobre os jovens da "Geração @” em distintos espaços e distintas rotinas contemporâneas: do quarto; da escola; do ócio; das migrações; das subculturas; e do ciberespaço. Para o autor, dos anos 90 em diante, a vida em casa é cada vez mais vivida no quarto e durante mais tempo, 
com os jogos, o computador, o telefone móvel, o uso das comunicações instantâneas. Obviamente temos que levar em consideração que tais características ressaltadas pelo autor, também estão atravessadas por condições sociais de classe, etnia, lugar, gênero e religião, entre outras. Sobre os jovens no espaço escolar, a obrigatoriedade da escolarização é vista por estudiosos como uma das causas do aparecimento da ideia de juventude num sentido universal. Cada vez mais (em tempo e em número) a juventude está na escola e se constrói nela. Por outro lado, os espaços de ócio também são destacados por configurarem lugares específicos de expressão da juventude, onde o consumo, o estilo e a distinção destacam identificações, diferenças e hierarquias, como no exemplo trabalhado por Thornthon (1996), sobre as culturas clubbers. Num outro ponto significativo, Feixa discorre sobre a relação entre jovens e os processos migratórios, destacando que, do ponto de vista geracional, estes movimentos ganharam outros sentidos, outros objetivos e outras formas de perceber o deslocamento, a distância, o lugar de saída e o de chegada, assim como passaram a usufruir das possibilidades de sobreposição de sua socialização on-line ou off-line. Sobre as subculturas, ou as culturas do estilo, elas continuam emergindo e se esvaindo ao fluxo dos interesses das identificações coletivas, das resistências e dos contextos articulados pela socialização de sua comunicação agora fortemente presente no ciberespaço. Aliás, Feixa lembra Don Tapscott (1998), para falar dos nativos digitais, ou seja, de como os "meninos e meninas dos noventa foram a primeira geração que chegou à maior idade na era digital" (p. 186). Embora também cite Manuel Castells (1999), para considerar que há aí "brechas digitais", ou seja, que nem todos da mesma geração têm o mesmo envolvimento com a rede e que é preciso levar em consideração o nível educativo, o grupo de idade e o nível de renda como marcadores das prováveis diferenças na intensidade deste envolvimento e sua relação com o consumo, Feixa acrescenta que há diferenças de gênero e faixa etária, bem como de escolha do tipo de aparelhos através dos quais eles se conectam, dos modos e dos motivos pelo que fazem, bem como o tempo que gastam com isto, mesmo que, de fato, de alguma maneira o envolvimento com o mundo digital faça parte das suas lógicas, dos modelos de convívio, das práticas e dos desejos dos diferentes nativos digitais ao redor do mundo.

Talvez o maior desafio desta entrada analítica pela geração seja captar as simultaneidades e as rupturas de tais ciclos. Na parte denominada de "Relatos", Feixa se concentra na trajetória biográfica de uma interlocutora de pesquisa. A estratégia foi partir da "vida real de uma jovem, cuja viagem à vida adulta nos servirá para refletir sobre as formas e conteúdos da juventude na era digital. (...) projetando sobre 
uma história de vida concreta as condições sociais e as imagens culturais que se projetam sobre toda uma geração (p. 205)". Ele descreve que tal testemunho biográfico, foi elaborado a partir de nove sessões de encontros gravados com a mesma pessoa no curso de mais de uma década, entre 2000 (ela tinha 21 anos) e 2011 (tinha 32 anos). 0 resultado é um texto em primeira pessoa, ao estilo realista de sucessão de acontecimentos sobrepostos, em que não aparece a intervenção das questões feitas pelo interlocutor, apenas as longas e detalhadas narrativas e percepções da entrevistada, em formato autobiográfico, às vezes lembrando um diário pessoal. "Sua biografia não é só uma ilustração sugestiva da Geração @, senão também contém potentes doses de reflexividade sobre a condição juvenil na era contemporânea, condensadas em algumas frases cursivas" (p. 208). Por exemplo, a interlocutora é parte da geração que foi adolescente ou jovem quando se começou a utilizar o email como forma de comunicação e a internet como meio de informação; e adulta/jovem quando se começou a utilizar o facebook como forma de socialização e se intensificou o uso da rede e das tecnologias digitais como meio de comunicação, informação, lazer e trabalho. Nestes trânsitos de percepção, de distanciamento com a geração ou a juventude na qual ela viveu a adolescência, a interlocutora avalia como vê as diferenças entre a sua experiência com relação aos adolescentes de hoje, dizendo que estes fazem uso excessivo das tecnologias, que não investem na conquista pela autonomia financeira e residencial com relação aos pais, entre outras questões, que para ela são marcas de diferenças geracionais, ainda que ela mesma se considere jovem e a um passo da vida adulta. Por exemplo, ela critica a forma de manifestação política dos jovens da atualidade e de forma melancólica diz que a juventude atual não é mais politicamente contestadora como fora no seu tempo, o que parece um modo recorrente de se marcar uma ideia de consciência, de diferença e de hierarquia entre gerações. Tais considerações nos colocam de novo diante das implicações do conceito de geração e até onde ele pode nos levar, quando o desafio é pensar a juventude.

Por fim, de que fenômeno nós falamos se não daquele que se constrói a si próprio ou que também construímos e que nem por isto é fábula? Em suas considerações finais, Feixa diz que temos presenciado "o nascimento, o crescimento, apogeu e crise da juventude, como conceito e como realidade social" (p. 313). Falando de sua experiência em um recente congresso internacional com especialistas de diferentes áreas médicas e psicológicas, educacionais e sociais, em que o foco esteve na adolescência, nos hormônios, nos neurônios, nas mudanças corporais e cerebrais, Feixa constata que os estudos sobre jovens vão e voltam à adolescência e a questão biológica. Por outro lado, para além 
das imposições classificadoras de antes, como as de hoje, o objetivo daqueles, os denominados jovens, tem mais a ver com aprender a se mover enquanto a vida passa, o que só acontece quando interatuam com os denominados adultos,que pela ordem das coisas aprenderam a se mover antes deles. Feixa questiona, "pode ser hoje a juventude algo mais que uma etapa da vida?" (p. 318). Esta não é uma assertiva conclusiva, mas um questionamento chave para abertura de muitas outras possibilidades de investigação, num momento e em contextos em que a noção de juventude é diluída ou reiterada a depender dos valores, dos atores e das disputas sociais.

\section{Referências}

CASTELLS, Manuel. La era de La información. La sociedade red (vol1). Madrid: Alianza, 1999.

DEBERT, Guita A Dissolução da Vida Adulta e a Juventude como Valor. Horizontes Antropológicos, Porto Alegre, ano 16, n. 34, p. 49-70, jul./dez. 2010.

FEIXA, Carles (1998). De Jóvenes, Bandas y Tribos: antropologia de La juventud. Barcelona, Editorial Ariel, 1998.

MARTIN-BARBERO, Jesus. A mudança na percepção da juventude: sociabilidade, tecnicidades e subjetividades entre jovens. In: BORELLI, Silvia \& FREIRE FILHO, João (orgs.). Culturas juvenis no século XXI. São Paulo, Educ. 2008.

TAPSCOTT, Don. Growing Up Digital: the rise of the net genereation. New York, McGrfeaw-Hill, 1998.

THORNTHON, Sarah. Club Cultures: music, media and subcultural capital. Middletown, Wesleyan U. P., 1996.

Recebido em 03 de março de 2016

Aprovado em 04 de abril de 2016 